\title{
Spontaneous closure of ventricular septal defect in a case of double outlet right ventricle
}

\author{
B MARINO, F LOPERFIDO, C SAVINO SARDI
}

From the Department of Cardiology and the Department of Pathology, Università Cattolica S Cuore, Policlinico A Gemelli, Rome, Italy

SUMMARY A 5 year old child, previously diagnosed as having tetralogy of Fallot, was admitted to. hospital in severe congestive heart failure. The electrocardiogram showed left anterior hemiblock and incomplete right bundle-branch block, neither of which was previously present. The child diedo in intractable congestive heart failure and the necropsy showed a double outlet right ventricle with_. complete spontaneous closure of the subaortic ventricular septal defect by fibrous tissue. The $e_{\subseteq}$ possible mechanism involved in the production of this unusual complication of double outlet right ventricle is discussed, together with an explanation for the electrocardiographic changes.

It is well known that an isolated ventricular septal defect can reduce in size spontaneously, and even close completely. ${ }^{1-3}$ Occasionally, this development has been described in patients with complex congenital heart disease, in whom the ventricular septal defect was physiologically advantageous such as the "classic" double outlet right ventricle, that is with bilateral conus, ${ }^{4-6}$ or tricuspid atresia. ${ }^{78}$ Conversely, complete spontaneous closure of a ventricular septal defect has never been described, to our knowledge, in patients with tetralogy of Fallot or with double outlet right ventricle and infundibular features of Fallot's tetralogy.

We report the clinical and anatomical findings of a case of double outlet right ventricle with some infundibular features of Fallot's tetralogy, in which there was spontaneous closure of the ventricular septal defect.

\section{Case report}

A 5 year old girl was born with a cyanotic cardiac defect. She was admitted to our hospital in congestive heart failure.

A heart murmur had been heard since birth. Cyanosis appeared when she was 5 months old. At 3 years of age she underwent a right heart catheterisation in another institution which disclosed tetralogy of Fallot. The electrocardiogram showed right ventricular hypertrophy including QRS right axis deviation (Fig. 1A). No surgical procedure was performed at that time. On admission to our unit, neither the catheterisation data nor the angiogram were available.

Physical examination showed a very ill child with blood pressure of $90 / 40 \mathrm{mmHg}$, pulse rate of $130 \%$ beats/min, and respiratory rate of $35 / \mathrm{min}$. She weighed $14 \mathrm{~kg}$ and was $105 \mathrm{~cm}$ tall. Mild cyanosis and $\overrightarrow{\overrightarrow{7}}$ dyspnoea were noted. The neck veins were distended. $\frac{0}{3}$ There was oedema at the ankles, hepatomegaly, ascites, and bilateral pleural effusions. The precor=0 dium was hyperactive. The first heart sound was normal and the second sound was single. A 3/6 ejec- $-\bar{D}$ tion systolic murmur and a third heart sound were heard in the third left intercostal space on the sternag border.

The chest $x$-ray film showed cardiac enlargement pulmonary venous congestion, bilateral pleural effusions, and a left aortic arch.

The electrocardiogram recorded on admission (Fig $\frac{\square}{\square}$ 1B) showed normal sinus rhythm, PR interval $0.18 \mathrm{~s}$ left atrial enlargement, QRS width $0.08 \mathrm{~s}$, and QRSN mean frontal axis $-60^{\circ}$. The QRS pattern indicated left anterior hemiblock; QRS morphology was Qrs $\mathrm{QS}$, and $\mathrm{rS}$ in V1, V2, and V6, respectively, indicat $-\mathrm{\omega}$ ing a posterior, rightward, and counterclockwise inscription of the QRS forces in the transverse plane?

Another electrocardiogram was recorded four day象 later (Fig. 1C) and disclosed an incomplete right ven =tricular conduction defect ( $\mathrm{qR}$ morphology in $\mathrm{V} 1 \frac{\mathrm{O}}{\mathrm{O}}$ with tall $R$ wave and mild increase in $Q R S$ width). $A$ D more pronounced superior deviation of the QRS axi was also evident.

The M-mode echocardiogram disclosed the pres? ence of two enlarged ventricles with two atrioventricus 

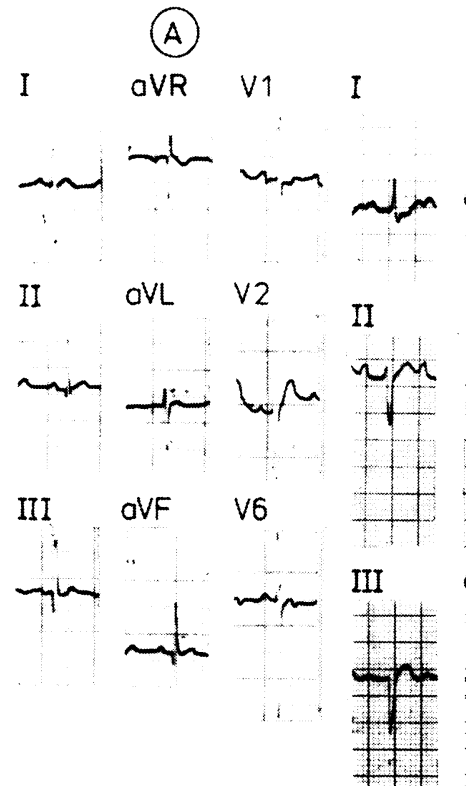
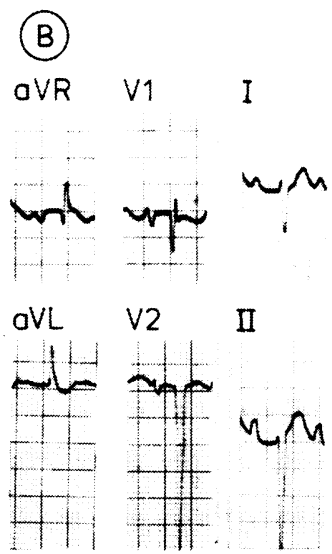

aVL V2

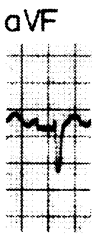

(C)

aVR V1 lar and semilunar välves. Aortic overriding was present.

Because of the poor clinical state of the child, heart catheterisation was not performed. On the fifth day after admission she died because of pulmonary oedema.

\section{ANATOMICAL FINDINGS}

The heart was in situs solitus of the atria, with laevocardia and normal systemic and pulmonary venous drainages. The atrioventricular connection was concordant and the atrioventricular valves were normal. The left atrioventricular valve was between the left atrium and left ventricle and it had no communication with the right ventricle. The two ventricles were enlarged. Hypertrophy of both left and right ventricular walls was present. Mural thrombi were found in the left ventricular cavity.

The type of ventriculoarterial connection was a double outlet right ventricle, the aorta originating entirely from the right ventricle with a muscular rim separating the tricuspid and aortic valves (Fig. 2B).

The right ventricular outflow tract showed an anterior and cephalad deviation of the infundibular septum. The malalignment of the infundibular septum with the rest of the muscular septum determined an infundibular pulmonary stenosis, as observed in Fallot's tetralogy.

The left ventricular outflow tract (Fig. 2B) was atretic because of the presence of accessory endocardial fibrous tissue. The mitral valve was separated from the aortic valve by endocardial fibrous tissue without any muscular component.

There was no ventricular septal defect; instead the ventricular septum was intact because the accessory fibrous tissue extended from the posterior and left aortic cusps to the muscular septum (Fig. 2A).

The atrial septum showed a large patent foramen ovale and an aneurysm from the left to the right of the Viesseux valve.

On macroscopical examination signs of acute pulmonary oedema were evident; histological features of chronic venous hypertension were observed.

\section{Discussion}

Our case was a double outlet right ventricle de facto with some infundibular features of tetralogy of Fallot, such as malalignment of the infundibular septum with the rest of the muscular septum and mitroaortic fibrous continuity. According to Anderson et al., 9 double outlet right ventricle as a type of ventriculoar- 


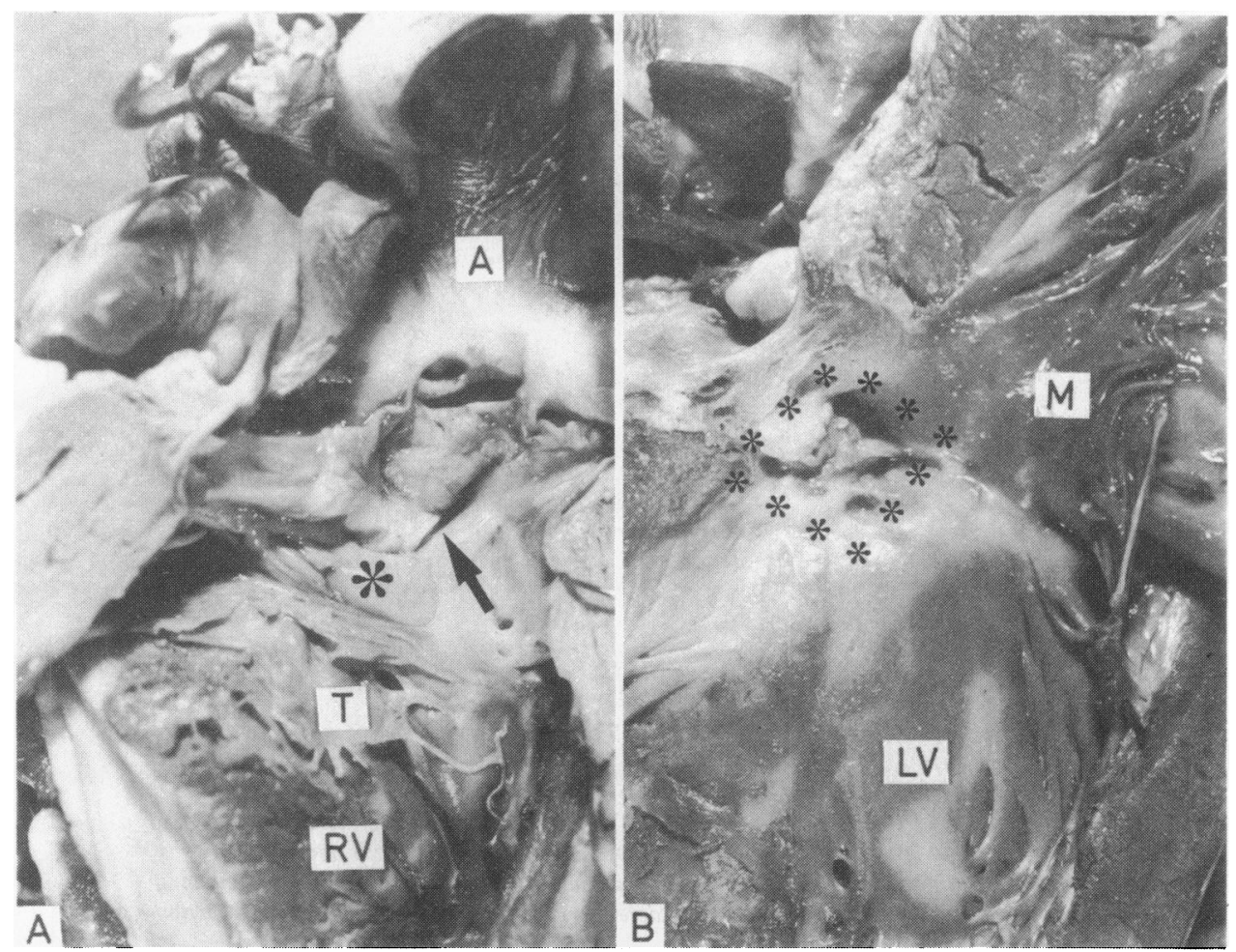

Fig. 2(A) Posterior outlet of the right ventricle $(R V)$ : the aorta $(A)$ arises entirely from the right ventricle. A muscular rim (*) separates tricuspid $(T)$ and aortic $(A)$ valves. A fibrous membrane (arrow) is attached superiorly to the posterior and lefi aortic cusps and inferiorly to the muscular septum, probably obstructing a previous ventricular septal defect. (B) Left ventricular $(L V)$ view; the $L V$ outflow tract, encircled by symbols $(\star)$, is atretic because of the presence of endocardial fibrous tissue separating the aortic and mitral (M) valves.

terial connection can coexist with the infundibular morphology of Fallot's tetralogy.

In our case ventricular septal defect was absent, accessory fibrous tissue extending from the aortic cusps to the muscular septum. Direct evidence of the previous existence of ventricular septal defect in this patient was not available at the time of our observation. Circumstantial evidence, however, of a previous ventricular septal defect was the left ventricular dilatation and hypertrophy, since the left ventricle would be hypoplastic if it had not previously had an outlet. Furthermore, left ventricular wall hypertrophy might be produced by progressive left ventricular outflow obstruction, that is by progressive obstruction of a communication between the two ventricles.

The reduction in size of physiologically advantageous ventricular septal defect has been described in several cases of double outlet right ventricle with bilateral conus. ${ }^{4-6}$ In such cases, a muscular subaortic conus, separating mitral and aortic valves and closely related to the ventricular septal defect, was considered to be the anatomical factor leading to the ventricular $\overline{0}$ septal defect ${ }^{6}$ by fibrous and/or muscular tissue.

Spontaneous closure of ventricular septal defect has $\delta$ not been reported in patients with double outlet right $₹$ ventricle without subaortic conus. This event is 웅 exceptional also in tetralogy of Fallot. An obstructive $\supset$ ventricular septal defect is rarely observed in Fallot's tetralogy: anomalous accessory tricuspid tissue ${ }^{1011}$ or $\overline{\hat{N}}$ anomalous attachment of the mitral valve to the ven- $\odot$ tricular septum, as in endocardial cushion defects, ${ }^{12} \mathrm{~N}$ have been described as causes of ventricular septal $\mathbb{\omega}_{\mathrm{W}}$ defect obstruction in tetralogy of Fallot.

In our case, the closure of the ventricular septalco defect was not caused by abnormalities of the $\frac{}{\Phi}$ atrioventricular valves. We suggest that the closure $\stackrel{?}{+}$ had been brought about by progressive growth of the $T$ accessory fibrous tissue extending from the aortic 0

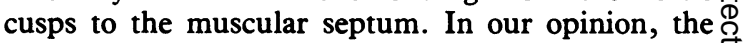

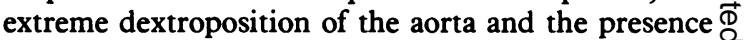
of a muscular rim separating the tricuspid and aortic $\bar{O}$ valves were predisposing factors to the closure of the 
left side of the bulboventricular foramen in this patient.

The evolution of the electrocardiogram in this patient is interesting: that recorded at the age of 3 years suggested right ventricular enlargement. During our observation, the electrocardiogram evolved from a left anterior hemiblock to an incomplete right ventricular conduction defect, associated with a more pronounced superior $\mathrm{QRS}$ axis orientation. It is well known that spontaneous closure or reduction in size of an isolated ventricular septal defect may affect the conducting system, with eventual development of left anterior hemiblock. ${ }^{13} \mathrm{We}$ suggest that the evolution of the electrocardiogram in our case could be the result of widespread progressive fibrosis in the area of the inferior rim of the ventricular septal defect, causing early electrical delay in anterolateral ramifications of the left bundle-branch and subsequently in the right bundle-branch. Late appearance of a right ventricular conduction defect associated with a higher degree of block in the left anterolateral ramifications seems to validate this opinion.

We acknowledge Dr M J Maitre (Madrid), Dr M Quero (Madrid), and Dr R Calabrò (Naples) for reviewing this manuscript.

\section{References}

1 Glancy DL, Roberts WC. Complete spontaneous closure of ventricular septal defect: necropsy study of five subjects. Am F Med 1967; 43: 846-53.

2 Suzuki H. Spontaneous closure of ventricular septal defects. Anatomic evidence in six adult patients. Am $\mathcal{F}$ Clin Pathol 1969; 52: 391-402.

3 Schott GD. Documentation of spontaneous functional closure of a ventricular septal defect during adult life. $\mathrm{Br}$ Heart $\mathcal{F}$ 1973; 35: 1214-6.
4 Rao PS, Sissman NJ. Spontaneous closure of physiologically advantageous ventricular septal defects. Circulation 1971; 43: 83-90.

5 Serratto M, Arevalo F, Goldman EJ, Hastreiter A, Miller RA. Obstructive ventricular septal defect in double outlet right ventricle. Am f Cardiol 1967; 19: 457-63.

6 Mason DT, Morrow AG, Elkins RC, Friedman WF. Origin of both great vessels from the right ventricle associated with severe obstruction to left ventricular outflow. Am F Cardiol 1969; 24: 118-24.

7 Roberts WC, Morrow AG, Mason DT, Braunwald E. Spontaneous closure of ventricular septal defect: anatomic proof in an adult with tricuspid atresia. Circulation 1963; $27: 90-4$.

8 Rao PS. Natural history of the ventricular septal defect in tricuspid atresia and its surgical implications. $\mathrm{Br}$ Heart $\mathcal{F}$ 1977; 39: 276-88.

9 Anderson RH, Allwork SP, Ho SY, Lenox CC, Zuberbuhler JR. Surgical anatomy of tetralogy of Fallot. $\mathcal{F}$ Thorac Cardiovasc Surg 1981; 81: 887-896.

10 Hoffman JIE, Rudolph AM, Nadas AS, Gross PE. Pulmonic stenosis, ventricular septal defect, and right ventricular pressure above systemic level. Circulation 1960; 22: 405-11.

11 Mesko ZG, Wagner HR, Subramanian S. Tetralogy of Fallot: occlusion of the ventricular septal defect due to accessory tricuspid valve leaflet and an associated membranous aneurysm. Eur $\mathcal{F}$ Cardiol 1978; 7: 257-62.

12 Van Praagh R, Corwin RD, Dahlquist EH Jr, Freedom RM, Mattioli L, Nebesar RA. Tetralogy of Fallot with severe left ventricular outflow tract obstruction due to anomalous attachment of the mitral valve to the ventricular septum. Am f Cardiol 1970; 26: 93-101.

13 Somerville J. Congenital heart disease-changes in form and function. Br Heart $\mathcal{F}$ 1979; 41: 1-22.

Requests for reprints to Dr Bruno Marino, Via della Camilluccia 741, 00135 Roma, Italy.

\section{Notice}

\section{British Cardiac Society}

The Autumn Meeting will be held at Wembley on 21 and 22 November 1983, and the closing date for abstracts will be 26 July 1983 .

The Annual General Meeting for 1984 will take place in Leicester on 11 and 12 April 1984, and the closing date for receipt of abstracts will be 3 January 1984.

The Autumn Meeting 1984 will be held on 3 and 4 December 1984, and the closing date for receipt of abstracts will be 15 August 1984 . 